\title{
"Do the Germans Really Work Six Weeks More than the French?" - Measuring Working Time with the Labour Force Survey in France and Germany
}

\author{
Thomas Körner ${ }^{1}$ and Loup Wolff ${ }^{2}$
}

\begin{abstract}
Measuring working time is not only an important objective of the EU Labour Force Survey (LFS), but also a highly demanding task in terms of methodology. Against the background of a recent debate on the comparability of working time estimates in France and Germany, this article presents a comparative assessment of the measurement of working time in the Labour Force Survey obtained in both countries. It focuses on the measurement of the hours actually worked, the key working-time concept for short-term economic analysis and the National Accounts. The contribution systematically analyses the differences in the measurement approaches used in France and Germany in order to identify the methodological effects that hinder comparability. It comes to the conclusion that the LFS overstates the difference in hours actually worked in France and Germany and identifies question comprehension, rounding, editing effects, as well as certain aspects of the sampling design, as crucial factors of a reliable measurement in particular of absences from work during the reference week. We recommend continuing the work started in the European Statistical System towards the development of a model questionnaire in order to improve cross-national harmonisation of key variables such as hours actually worked.
\end{abstract}

Key words: Nonsampling errors; measurement error; questionnaire design; working hours; international comparability.

\section{Measuring Working Time as an Objective of the Labour Force Surveys}

Measuring working time is one of the most important of the numerous objectives of Labour Force Surveys (LFS). In many countries, working-time estimates based on the LFSs are vital data for inputting into the National Accounts (e.g., to calculate indicators on the volume of work and labour productivity) as well as for a whole range of socioeconomic analyses. The LFS carried out in the member states of the European Union provide data regarding two main working-time concepts, both of which are defined according to the Resolution of the Eighteenth International Conference of Labour Statisticians (ICLS) endorsed in 2008 (International Labour Organization, ILO 2008) - the hours actually worked and the hours usually worked.

${ }^{1}$ Federal Statistical Office Germany, 65180 Wiesbaden, Germany. Email: thomas.koerner@destatis.de

${ }^{2}$ Ministére de la culture et de la communication, 182 rue Saint Honoré, 75033 Paris cedex 01. Email: loup.wolff@culture.gouv.fr

Acknowledgments: This contribution is a revised, updated and expanded version of two papers presented at the 7th European Workshop on Labour Force Survey Methodology, Madrid, 10-11 May 2012. The authors would like to thank the anonymous reviewers and the associate editor for their useful comments. The views expressed in this article are those of the authors and not necessarily those of their institutions. 
In practice, measuring the hours actually worked and those usually worked can only be based on household surveys, since the employed persons are the only respondents able to quantify the number of hours they actually and usually work. It could be suggested that time-use surveys are better than LFSs for this purpose. However, in this respect, the major disadvantage of time-use surveys is that, in comparison to the LFSs, they provide limited labour market information, have a small sample size and long intervals between the survey waves, do not cover the entire year, and do not use the concept of the reference week.

This explains the widespread use and key role of LFSs in measuring working time, despite the fact that LFSs often do not allow extensive questionnaire space or interviewing time for questions on specific topics such as working time. The strengths of LFS data are that they are based on large samples, they are able to provide timely and intra-annual data, that they cover all economic activities, including formal and informal employment, and that they are (at least in theory) in a position to implement the concepts as defined in the ICLS Resolution.

Nevertheless, the difficulties in measuring working time are regularly seen in the results of LFSs. There are often discrepancies between the results of the LFS and the National Accounts. The results regarding hours actually and hours usually worked are often inconsistent and international comparability is limited. Sometimes such (apparent or real) inconsistencies cause controversy, as in the case of the results for France and Germany. In 2012, a study based on Eurostat tabulations noted that the hours actually worked were much lower in France compared to Germany (Coe-Rexecode 2012). At the time, a lively debate ensued: French newspapers such as Libération, Les Echos and Le Figaro were incredulous and investigated the reliability of the study. The criticism was aggravated even further due to the fact that the working-time estimates in the National Accounts show inverted differences. The findings continue to provoke intense debate even today (Coe-Rexecode 2014).

Despite this controversy, the problem of measuring working time in LFSs is addressed surprisingly rarely in the literature. Still, the issues around measurement do feature in the discussion: in a broad overview, Mata-Greenwood (2001, 9-11) mentions recall errors, proxy errors, question comprehension issues and social desirability bias. While these effects may lead to over- as well as underestimations of working time, most contributions assume that, generally speaking, the effects lead to a underestimation of absences in the responses to the hours actually worked (for an overview, see OECD 2004).

As mentioned previously, empirical studies on the accuracy of working-time estimates are rare. Regarding the measurement of the hours actually worked, a number of studies compare data from LFS using a question covering the entire reference week with diarybased measurement approaches, mostly implemented in the context of time-use surveys. In most cases, the LFS-based estimates are $2 \%$ to $10 \%$ higher than the respective diary information (see e.g., Niemi 1993; Robinson and Bostrom 1994; Robinson et al. 2011). Smaller differences were found by Williams (2004), in whose analysis the LFS estimates were only $1.6 \%$ higher than time-use survey data, and by Frazis and Stewart (2004), who found only small differences between LFS and time-use survey data. In addition to a number of methodological limitations relating to the comparison of time-use survey and LFS data, all these studies have the drawback that they either completely exclude those employed persons who were not at work during the reference week from their analyses or 
at least have difficulties in comparing data based on reference weeks. Nevertheless, people who are employed but not at work in the reference week need to be included in the comparative analysis, as it is often assumed that absences due to holidays or illness have a major impact on the accuracy of working-time measurements. An international aggregatelevel comparison of estimates on hours actually worked (including absences) also shows higher values for LFS-based results, compared to administrative data (Fleck 2009, 27).

A similar, but less pronounced, tendency to produce higher working-time estimates has also been confirmed by a number of studies regarding the hours usually worked and the contractual hours of work. These studies are based on comparisons with establishment survey data (Williams 2002) and administrative registers (Villund 2009). For instance, in the case of the hours usually worked, the most common problem is that the hours usually worked are difficult to collect from establishment surveys, as employers ordinarily only have the information about the contractual hours of work and not the hours usually worked.

Unlike most previous studies, this analysis is not primarily based on comparisons with other data sources, be it time-use surveys or administrative data. After an overview of the relevant statistical concepts and their operationalisation in France and Germany (Section 2), our analytical point of departure is a comparison of the LFS results from France and Germany. We discuss whether these results are consistent with other data sources regarding important working-time components such as entitlement to paid leave, sick leave, and the number of public holidays (Section 3). Given that the LFS in Germany and France use quite different measurement approaches, we then attempt to identify possible sources of error that may contribute to the differences observed (Section 4).

\section{Working-Time Concepts and their Implementation in the Labour Force Surveys of France and Germany}

Conceptually, the measurement of working time in official statistics is based on the Resolution Concerning the Measurement of Working Time adopted by the Eighteenth International Conference of Labour Statisticians (ICLS) in 2008 (ILO 2008). This Resolution distinguishes no less than seven concepts of working time: the hours actually worked, the hours usually worked, the hours paid for, the normal hours of work, the contractual hours of work, the overtime hours of work, and the absence from work hours. As acknowledged by the Resolution, the variety of these seven concepts makes it impossible to capture all of them in one single data source: the Resolution suggests using LFSs to measure the hours actually worked and the hours usually worked, and to use establishment surveys as well as administrative registers to measure the hours paid for, the contractual hours of work, and the normal hours of work. This distinction is important, as it highlights the fact that there are few reference data sources to compare the LFS results for the hours actually worked and the hours usually worked.

The concept of hours actually worked is the key concept of the ICLS Resolution and it is closely related to the definition of the other concepts, in particular the hours usually worked. The hours actually worked refer to "the time spent in a job for the performance of activities that contribute to the production of goods and/or services during a specified short or long reference period" (ILO 2008, 43). The reference period for the LFSs, usually the 
reference week used for the measurement of the employment status, is also applied to working-time measurement.

Following the recommendation to use LFSs to measure the hours actually worked is not straightforward, as the ICLS definition is very complex, reflecting the complexity of the issue in national working-time regulations. Regarding the productive activities within the production boundary of the System of National Accounts (SNA), it contains at least nine distinct components to be included and seven components to be excluded when determining the hours actually worked (the definition of which is problematic in itself). Table 1 provides a simplified overview of the working-time components. In addition to the time spent actually carrying out the tasks that are part of the job, working time also includes the time spent preparing the work, waiting time, most travel time between work locations, time for work-related training, as well as short breaks other than the lunch break. Time spent on call is considered working time depending on the extent to which the worker is prevented from participating in other activities. Conversely, annual leave, sick leave, public holidays, other types of leave, as well as educational activities not required by the job and longer breaks are excluded from the hours actually worked.

For the hours usually worked, the same rules apply; they are defined as "the typical value of hours actually worked [. . .] over a long observation period of a month, quarter, season or year" (ILO 2008, 45).

In contrast to this complex definition, LFSs usually try to determine the number of hours actually worked and the hours usually worked with one single question each, tacitly assuming that the inclusion and exclusion criteria are similar to respondents' everyday-life perceptions (and can consequently be clarified with a short instruction). Nevertheless, the resulting questions, usually of the type "How many hours did you actually work in the week from [. . . ] to [. . .]?" are highly demanding cognitively, even if one assumes that the distinctions made in the ICLS Resolution are close to those in the respondents' minds (see Chapter 4).

The LFSs is carried out in all European Union member states, as well as in EFTA countries, in the Former Yugoslav Republic of Macedonia, and in Turkey. It is based on a number of European legal acts, the main one being the Council Regulation No. 577/1998. The legal acts are based on the principle of output harmonisation, that is, they specify the output data to be provided to Eurostat, but give a certain leeway to take national circumstances into account for survey implementation. The regulations in particular specify the required precision (and indirectly the effective sample size), the equal distribution of the sample over the calendar weeks, the variables and items to be provided as well as the transmission deadlines. The actual survey implementation, including the sampling frame, question wording, data collection modes and so on, is largely not regulated by law (although some provisions exist regarding the measurement of labour status). The member states are provided with a set of recommendations for implementation, however (for an overview of the LFS harmonisation strategy, see Körner 2012). Nevertheless, substantial differences exist regarding the operationalisation of the variables in questionnaires (see, e.g., Massarelli 2011) and the data collection modes applied (Blanke and Luiten 2014). The differences recently led to the development and joint international testing of model questionnaire modules for key variables of the core LFS (such as labour status and working time) and ad-hoc modules. Table 2 provides an 
Table 1. Components to be considered for the measurement of hours actually worked (adapted from ILO 2008)

Hours actually worked...

\section{. . . include time spent}

- carrying out the tasks and duties of the job (in any location and during periods not dedicated to work)

- cleaning or maintaining tools, instruments, processes, changing time, decontamination or washing-up time

- purchasing or transporting basic materials

- waiting for business, customers or patients (as part of working-time arrangements)

- on temporary interruptions of a technical, material or economic nature

- on on-call duty (depending on the extent to which other activities and movements are restricted)

- on training and skills enhancement (required by the job)

- travelling between work locations (e.g., business trips)

- on short breaks

overview of important design elements of the LFS in France and in Germany (regarding the situation in other member states, see the summary in Eurostat 2013).

Regarding the number of hours actually worked, the legal basis of the LFS currently does not include anything other than the name of the variable (HWACTUAL) and the specification that the "number of hours actually worked during the reference week in the main job" (Regulation 377/2008) is to be collected and that the persons employed, but not at work in the reference week, are to be coded " 00 ". The recommendations for the implementation of the questionnaire basically summarise the ICLS Resolution (still currently the resolution adopted in 1962), without giving any recommendations on questionnaire implementation.

Consequently, there is considerable variation in the measurement instruments used for data collection, and this is also the case for working time. France and Germany are particularly interesting cases for comparison, as they can be considered extreme cases on the continuum between very detailed measurement involving many questions (France) and a very limited number of questions (Germany).

Like most other member states, the German questionnaire basically uses a singlequestion approach with one question asking for the hours actually worked in the reference week, while the French LFS questionnaire includes a detailed sequence of questions introducing the concept and the situation in the reference week.

The presentation of the findings from the present study to the working committees of the European Statistical System has already triggered further development work: since April 2013, a Eurostat task force has been trying to improve and further harmonise the measurement of working time in the LFS. The task force is developing a model 
Table 2. Important design elements of the French and the German LFS (2012)

\begin{tabular}{|c|c|c|}
\hline & France & Germany \\
\hline $\begin{array}{l}\text { Net quarterly sample size } \\
\text { (persons } 15-74 \text { years) }\end{array}$ & 106,000 & 129,500 \\
\hline Quarterly sampling rate & $0.25 \%$ & $0.25 \%$ \\
\hline Sample design & Area sampling & $\begin{array}{l}\text { One-stage area sample } \\
\quad \text { (average size of sampling } \\
\text { districts } 9 \text { dwellings) }\end{array}$ \\
\hline Sampling frame & $\begin{array}{l}\text { Tax register } \\
\quad(\text { habitation tax })\end{array}$ & $\begin{array}{l}\text { Census } 1987 \text { for former } \\
\text { territory/Central Population } \\
\text { Register } 1990 \text { for new federal } \\
\text { states/Annual updates based } \\
\text { on the statistics of building } \\
\text { permissions }\end{array}$ \\
\hline Rotation scheme & $\begin{array}{l}\text { Quarterly rotation } \\
\text { (6 consecutive } \\
\text { quarters) }\end{array}$ & $\begin{array}{l}\text { Annual rotation only } \\
\text { (four consecutive years) }\end{array}$ \\
\hline Reference week & $\begin{array}{l}\text { Fixed reference weeks } \\
\quad(\text { see Chapter } 4)\end{array}$ & $\begin{array}{l}\text { Sliding reference weeks } \\
\quad \text { (see Chapter } 4)\end{array}$ \\
\hline Response rate & $84.7 \%$ & $98.2 \%$ \\
\hline $\begin{array}{l}\text { Mandatory or voluntary } \\
\text { response }\end{array}$ & Mandatory & Mandatory \\
\hline Rate of proxy interviews & $29 \%$ & $25 \%$ \\
\hline $\begin{array}{l}\text { Data collection modes } \\
\text { first interview }\end{array}$ & CAPI & $\begin{array}{l}\text { CAPI, self-administered PAP, } \\
\text { Telephone interview }\end{array}$ \\
\hline $\begin{array}{l}\text { Data collection modes } \\
\text { follow-up interview }\end{array}$ & CATI, CAPI & $\begin{array}{l}\text { CAPI, self-administered PAP, } \\
\text { Telephone interview }\end{array}$ \\
\hline
\end{tabular}

questionnaire with the aim of improving the measurement of absences and achieving greater harmonisation. The first version of the model questionnaire has already been tested in several member states. The task force's approach is discussed in relation to our findings in Chapter 5.

\section{Assessing the Measurement of Working Time in France and Germany}

As mentioned in the introduction, the number of hours actually worked per year is a crucial indicator for the National Accounts. In some countries, the estimation for the National Accounts is derived directly from the LFS, while in others, like France and Germany, it is at least partly independent of the LFS (see Wanger 2013 for Germany and Lefèvre, Rakotomalala, and Toutlemonde 2012 for France). Table 3 shows that comparing working-time estimates is a delicate task, not only internationally, but also as regards comparisons between the LFS and the National Accounts. Starting with the working time of employed persons, it could be concluded that there is hardly any difference between France and Germany, according to the LFS. In contrast, in the National Account estimates, Germany registers a significantly lower number of hours actually worked per year $(-6.9 \%)$. The difference in the German results is not only due to the actual measurement of working time, but also to the deviations in the share of part-time workers. The LFS may 
Table 3. Number of annual hours actually worked per person in France and Germany (2012)

\begin{tabular}{llccr}
\hline & & Germany & France & $\begin{array}{c}\text { Relative } \\
\text { difference \% }\end{array}$ \\
\hline Employed persons & LFS (main job only) & 1,636 & 1,632 & 0.2 \\
& National Accounts & 1,393 & 1,489 & -6.9 \\
Employees & LFS (main job only) & 1,586 & 1,554 & 2.0 \\
& National Accounts & 1,297 & 1,402 & -8.1 \\
Full-time employees & LFS (main job only) & 1,863 & 1,684 & 9.6 \\
& National Accounts & 1,646 & not available & \\
Part-time employees & LFS (main job only) & 838 & 985 & -17.5 \\
& National Accounts & 634 & not available & \\
\hline
\end{tabular}

have difficulties comprehensively capturing marginal employees (Körner and Puch 2011). For this reason, the German National Accounts mainly use other sources, for instance the Employment Statistics Register, to estimate the number of full-time and part-time employees (in 2012, the share of part-time employees in Germany was $38.1 \%$ according to the National Accounts (volume of labour accounting) compared to only $27 \%$ according to the LFS). German media coverage often focuses on the low number of hours actually worked, as estimated by the National Accounts, suggesting that "Germans work comparatively little" (Groll 2014). In contrast, in France, the debate generally focuses on the LFS estimates for full-time employees, suggesting much longer working times in Germany (+9.6\%; Coe-Rexecode 2014).

Table 3 clearly demonstrates that much care must be taken in order to correctly interpret working-time indicators. When the aim is to identify the methodological effects leading to different working-time estimates, it is important to be able to distinguish the effects due to the actual measurement of working time in the survey and effects due to deviating structures for full-time and part-time employees. Against this backdrop, our article focuses on the measurement of hours actually worked in the LFS for the group of full-time employees. This not only makes the reference population more homogeneous, but also focuses on the group with the greatest impact on the average hours actually worked. Moreover, the focus on full-time employees makes it possible to make comparisons with regulations and collective agreements, for example, regarding the entitlements to paid leave and public holidays. It should be noted that the measurement of working time for part-time employees and self-employed is complicated for other reasons, which are however not elaborated on any further in this article (for a recent study, see Vallé et al. 2014).

Table 4 presents the distribution of hours actually worked in hour bands. The results already suggest some possible hypotheses regarding the methodological effects on the measurement of hours actually worked in France and Germany: France registers a higher proportion of full-time employees with 0-hour weeks (due to holidays, sickness or other reasons) or with less than 35 hours worked in the week. The modal value is 35 hours in France, the legal threshold beyond which any additional hours worked fall under the overtime regime. The German modal value is higher, equalling 40 hours per week. The differences of the distributions of hours actually worked in Germany and France, as shown in Table 4, require further investigation: full-time employees necessarily experience a certain number of shorter weeks (including weeks with zero hours) during the 
Table 4. Number of hours actually worked by full-time employees in hour bands by reference week (full-time employees; LFS 2012)

\begin{tabular}{lrrrrr}
\hline \multirow{2}{*}{$\begin{array}{l}\text { Hours actually worked } \\
\text { in the reference week }\end{array}$} & \multicolumn{2}{c}{ Germany } & & \multicolumn{2}{c}{ France } \\
\cline { 2 - 3 } \cline { 5 - 6 } 0 hours & in 1,000 & & & in 1,000 & $\%$ \\
$1-19$ hours & 2,973 & 11.5 & & 2,711 & 14.6 \\
$20-29$ hours & 390 & 1.5 & & 398 & 2.2 \\
$30-34$ hours & 531 & 2.1 & & 1,306 & 7.0 \\
35 hours & 1,267 & 4.9 & & 1,033 & 5.6 \\
$36-39$ hours & 1,131 & 4.4 & & 4,333 & 23.3 \\
40 hours & 4,210 & 16.3 & & 3,532 & 19.0 \\
$41-49$ hours & 8,916 & 34.5 & & 1,722 & 9.3 \\
50 hours or more & 3,864 & 14.9 & & 1,952 & 10.5 \\
Total & 2,575 & 10.0 & & 1,582 & 8.5 \\
& 25,854 & 100.0 & & 18,570 & 100.0 \\
\hline
\end{tabular}

year for various reasons including paid holidays, bank holidays, sickness, and so on. The measurement of these nontypical weeks is crucial for estimating the average number of hours actually worked per week. The accuracy of these distributions has to be established in order to guarantee the robustness of the aggregates.

\subsection{Absences Due to Sickness}

Regarding absences due to sickness, both the French and the German LFSs deliver consistent messages: almost 3\% of full-time employees were on sick leave for the whole reference week in 2012. The share of employees working a shortened week is also similar: around $1 \%$. These results lead to an estimation of 1.7 weeks of absence due to sick leave per full-time employee in Germany and 1.5 in France in 2012 (Table 5). These results are close to the calculations in the National Accounts in Germany (based on statutory health insurance data), which amount to 1.8 weeks of absence due to sick leave (IAB 2014).

\subsection{Absences Due to Holidays}

The measurement of sick leave in Germany and France provides coherent figures in both countries. The results contrast much more strongly regarding absences for holiday leave. On average, in any given week, $6.1 \%$ of full-time employees are absent from work in Germany on holiday leave. This proportion is much higher in France: $10.3 \%$. Working weeks shortened due to holiday leave are also more frequent in France (5.4\%) than in Germany (2.0\%).

These differences explain most of the discrepancies observed in Table 4: French fulltime employees more frequently report unworked or shortened weeks than Germans do. The sum of 6.3 weeks of absences due to holidays is reported in the French LFS, whilst only 3.6 weeks are declared in the German survey (Table 6).

Is this because French employees have more holiday entitlement than Germans? There is no direct empirical evidence for this. However, the total number of estimated weeks of absence due to holiday leave per full-time employee in Germany seems conspicuously low: only 3.6 weeks, whereas the volume of labour accounts, based on information from collective bargaining agreements, assumes a value of around 6 weeks (see IAB 2014; 
Table 5. Absences due to sickness (LFS, 2012)

$\begin{array}{ccc}\begin{array}{c}\text { Full-time } \\ \text { employees }\end{array} & \begin{array}{c}\text { with no work in } \\ \text { reference week } \\ \text { due to sick leave }\end{array} & \begin{array}{c}\text { with fewer } \\ \text { working hours } \\ \text { than usual } \\ \text { in the reference } \\ \text { week due to } \\ \end{array} \\ & & \text { sick leave }\end{array}$

\section{Germany}

Persons (in 1,000s)

Persons (in \%)

Average hours actually worked

Estimated sum of sick weeks (in 1,000)

Estimated weeks of absence due to sick leave per full-time employee

$\begin{array}{ccc}25,854 & 733 & 203 \\ 100 & 2.8 & 0.8 \\ 35.8 & 0.0 & 21.0 \\ 43,225 & 38,116 & 5,109\end{array}$

$\begin{array}{lll}1.7 & 1.5 & 0.2\end{array}$

\section{France}

\begin{tabular}{lccc}
\hline Persons (in 1,000) & 18,570 & 491 & 130 \\
Persons (in \%) & 100 & 2.6 & 0.7 \\
Average hours actually worked & 32.4 & 0.0 & 20.7 \\
$\begin{array}{l}\text { Estimated sum of sick weeks } \\
\quad \text { (in 1,000s) }\end{array}$ & 28,761 & 25,543 & 3,218 \\
$\begin{array}{l}\text { Estimated weeks of absence } \\
\quad \text { due to sick leave }\end{array}$ & 1.5 & 1.4 & 0.2 \\
\hline
\end{tabular}

Spitznagel 2003; Wanger 2013). According to the data compiled by the European Industrial Relations Observatory (EIRO), the number of days of paid leave is around 30 days in Germany (according to collective agreements) and significantly more than 25 days in France (statutory minimum), based on a five-day working week (Eurofound 2013, 18-19). Against these figures, the results for Germany presented in Table 6 seem implausible and indicate an underreporting of absences due to holiday leave in the German LFS.

Another factor explaining this situation is public holidays. We have analysed the weeks affected by a public holiday for both France and Germany. If French and German respondents respond accurately to the questions regarding their absences during the reference weeks, those whose reference week comprises a national public holiday should in a large majority report a shortened working week.

Table 7 shows that this is the case, but demonstrates also that the effect is much stronger in France than in Germany. In Germany, the working time during weeks affected by a national public holiday is only shortened by $7.6 \%$ compared to an average week. In France, the factor is multiplied by almost four: $26.5 \%$.

Table 8 confirms the suspicion of a declarative bias: while $78.1 \%$ of the full-time employees declared reduced working hours in reference weeks affected by a nationwide public holiday in France, this percentage is almost halved in Germany (40.1\%). German respondents declare fewer weeks with both total and partial absences from work. Similar measurement issues were also confirmed for the Italian LFS, in which the measurement of 
Table 6. Absences due to holidays (LFS, 2012)

$\begin{array}{ccc}\begin{array}{c}\text { Full-time } \\ \text { employees }\end{array} & \begin{array}{c}\text { with no work in } \\ \text { reference week } \\ \text { due to holiday }\end{array} & \begin{array}{c}\text { with fewer } \\ \text { working hours than } \\ \text { usual in the } \\ \text { reference week } \\ \text { due to holiday }\end{array} \\ & & \begin{array}{c} \\ \end{array}\end{array}$

\section{Germany}

\section{Persons (in 1,000s)}

Persons (in \%)

Average hours actually worked

Estimated sum of holiday weeks (in 1,000)

Estimated weeks of absence due to holidays per full-time employee

$\begin{array}{ccc}25,854 & 1,580 & 516 \\ 100 & 6.1 & 2.0 \\ 35.8 & 0.0 & 22.2 \\ 94,356 & 82,160 & 12,196\end{array}$

$\begin{array}{lll}3.6 & 3.2 & 0.5\end{array}$

\section{France}

Persons (in 1,000)

Persons (in \%)

Average hours actually worked

Estimated sum of holiday weeks (in 1,000s)

Estimated weeks of absence due to holidays

$\begin{array}{ccc}18,570 & 1,913 & 1,009 \\ 100 & 10.3 & 5.4 \\ 32.4 & 0.0 & 26.2 \\ 117,092 & 99,486 & 17,606\end{array}$

$\begin{array}{lll}6.3 & 5.4 & 0.9\end{array}$

absences due to public holidays was considerably improved after the introduction of an improved questionnaire (Loriga and Spizzichino 2013).

These pieces of evidence strongly suggest the existence of a declarative bias in Germany in comparison with France. German respondents are less likely to mention their days off due to holiday than the French. However, this assumption has not been verified for absences due to sickness.

Table 7. Average hours actually worked by reference week with/without public holiday, full-time employees (LFS, 2012)

\begin{tabular}{lcc}
\hline & Germany & France \\
\hline Average & 35.8 & 32.4 \\
\hline $\begin{array}{l}\text { Weeks with national public holiday } \\
\text { Diff (with average) }\end{array}$ & 33.1 & 23.8 \\
\hline $\begin{array}{l}\text { Weeks without any public holiday } \\
\text { (neither national nor regional) }\end{array}$ & $-7.6 \%$ & $-26.5 \%$ \\
Diff & 36.5 & 33.7 \\
\hline
\end{tabular}

(1) Not coinciding with a weekend in 2012;

Germany: Good Friday, Easter Monday, Labour Day, Ascension Day, Whit Monday, National Holiday, Christmas Day.

France: Easter Monday, Labour Day, Armistice Day, Ascension Day, Assumption Day, All Saint's Day, Christmas Day. 
Table 8. Full-time employees actually working less than usual in weeks with national public holidays (LFS, 2012)

Germany France

\begin{tabular}{|c|c|c|c|c|}
\hline \multicolumn{2}{|c|}{$\begin{array}{l}\text { Weeks with nationwide public holiday } \\
\text { total }\end{array}$} & in $1,000 \mathrm{~s}$ & 3,588 & 2,489 \\
\hline reduced working hours & & in $1,000 \mathrm{~s}$ & 1,440 & 1,944 \\
\hline due to any reason & & in $\%$ & 40.1 & 78.1 \\
\hline \multirow{4}{*}{ of which } & zero hours worked in the & in $1,000 \mathrm{~s}$ & 496 & 617 \\
\hline & reference week & in $\%$ & 13.8 & 24.8 \\
\hline & working time shorter than & in $1,000 \mathrm{~s}$ & 944 & 1,327 \\
\hline & hours usually worked & in $\%$ & 26.3 & 53.3 \\
\hline
\end{tabular}

There are multiple interpretations to explain this phenomenon: a cultural bias making it easier to declare holiday in France than in Germany? Or perhaps the questionnaires and the sample design of these surveys are to blame (see Section 4)? The effects of this bias are clearly visible in Figure 1: the number of hours actually worked in Germany and France fluctuate throughout the year, with drops during the holiday seasons. However, the peaks are much more pronounced in France than in Germany, due to the greater rate of declaration of absences from work.

\section{Understanding the Measurement Effects Leading to the Differences}

The previous section revealed a number of clearly implausible results regarding the number of hours actually worked. In contrast to the German figures, in which absences due

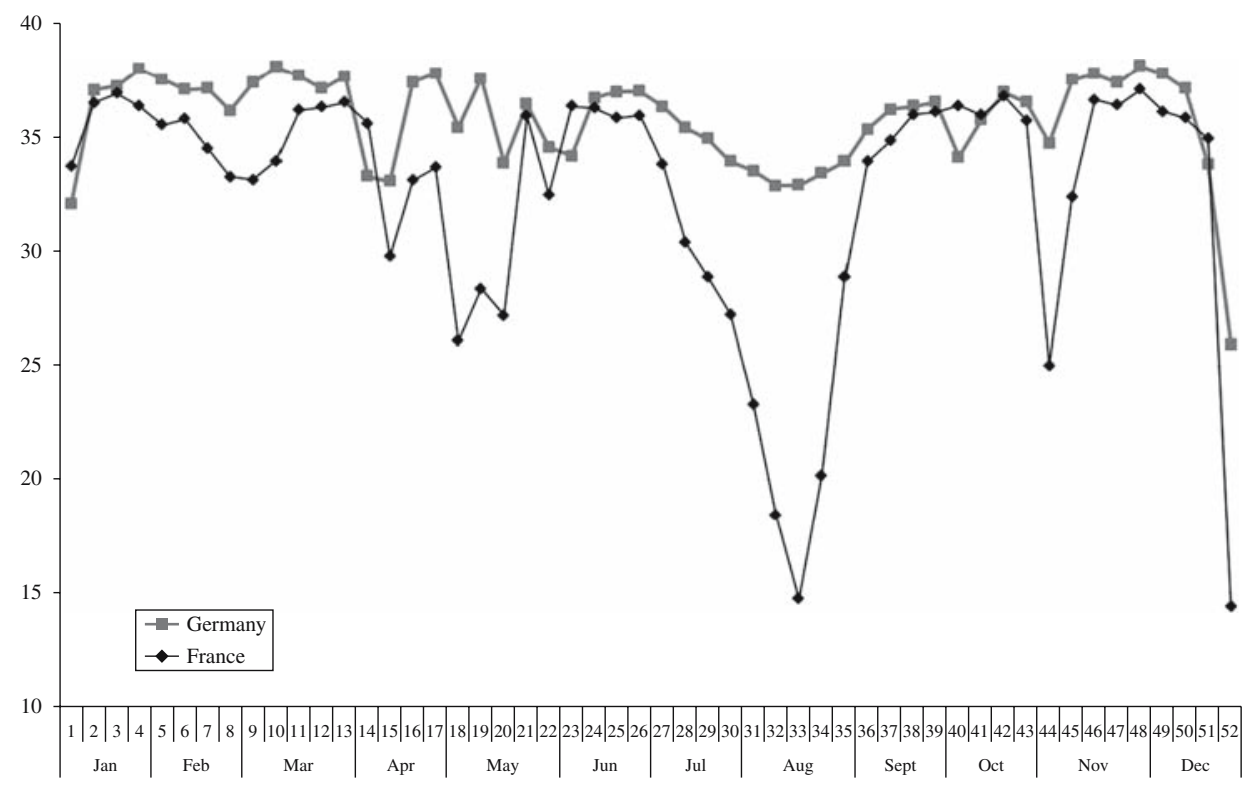

Fig. 1. Number of hours actually worked by reference week (full-time employees; LFS, 2012) 
to paid leave and public holidays are conspicuously rare, the results for France correspond more or less to expectations based on the legal entitlement to sick leave and the specific calendar situation in the year 2012. Following the comparative assessment of the results on hours actually worked, this chapter tries to identify possible methodological sources that may contribute to the differences in the French and German results.

We have tried to take into account all major sources of error that may apply in the case of the LFSs in Germany and France. Based on the usual error typologies (see, e.g., Groves 1989; Biemer and Lyberg 2003; Groves et al. 2009; Eurostat 2009), possible sources of error include bias due to the sampling design, frame coverage bias, nonresponse bias, measurement bias as well as bias introduced in data processing (e.g., editing and weighting). Given the large sample size of the LFS, we do not focus on sampling errors, considered marginal in magnitude compared to the deviations identified in Section 3. The $95 \%$ confidence interval for the average hours actually worked amounts to $+/-0.1$ hours in Germany and $+/-0.3$ hours in France (annual results; see Eurostat 2014b).

Most of the potential sources of bias are neither easy to identify nor easy to quantify. The analysis of bias requires dedicated experiments that are demanding in terms of their design (and frequently do not meet the expectations) and focus on a reduced number of specific measurement effects. No specific experiments were carried out for the present study. The purpose is instead to give an overview of the major contributors to the astonishing results introduced in Section 3. This analysis is broadly based on the regular LFS data as well as related methodological studies in both countries.

\subsection{Nonresponse Bias}

Nonresponse bias is a widely researched source of error. Nevertheless, in the case of measuring working time in the LFS in France and in Germany, it is obviously not of major importance. Survey participation is mandatory in both countries, which results in response rates of more than $80 \%$ in France and slightly more than $98 \%$ in Germany. The level of response alone leaves relatively little room for nonresponse bias. Regarding the effects described in Chapter 3, it also does not seem plausible to assume that nonresponse plays a major role in these effects, that is, it is unlikely that employed persons who were on holiday in the reference week are less likely to participate in the LFS ceteris paribus.

\subsection{Bias Due to the Sampling Design}

The EU-LFS has been specifically designed to measure variables showing seasonal variations. The number of hours actually worked in the reference week is a variable that is subject to particularly strong seasonal and calendar-specific variation. Bank holidays, typical periods when paid leave is taken, as well as the winter season directly translate into a reduction in the number of hours worked. The design of the LFS has been developed to take this variation into account and to produce genuine quarterly and annual results. EU Regulation No. 577/1998 lays down the basic rule that "the reference weeks are uniformly distributed throughout the whole year", that is, the number of sampling units per week is $1 / 52$ in each calendar week. In the case of hours actually worked, an unequal distribution of the sampling units over the calendar weeks can lead to biased results. For example, smaller sample sizes in typical holiday weeks could contribute to an 
overestimation of the annual averages of hours actually worked (if not corrected for by the weighting scheme).

France and Germany apply different rules to allocate the reference weeks, so it might be assumed that these differences impact upon the differential results regarding the hours actually worked. While France, like most other member states, uses fixed reference weeks, Germany (like the Netherlands and Slovenia) relies on the principle of sliding reference weeks. When using fixed reference weeks, each sampling unit is allocated to a specific calendar week when the sample is selected. The interview will refer to this specific week, no matter when it takes place. Under the principle of sliding reference weeks, the interview always refers to the week directly preceding the week in which the interview takes place. While the principle of the sliding reference week facilitates fieldwork organisation and may reduce memory bias, it usually leads to a certain variation of weekly sample sizes. In the German case, the weekly sample size varies between $0.8 \%$ and $3.0 \%$ of the annual sample, while in France the variation is between $1.7 \%$ and $2.1 \%$, close to the theoretical share of $1.9 \%$ (1/52). It should be noted that the variation in weekly samples in Germany, in addition to the effects of the sliding reference week, is also due to the fact that interviewers receive work packages with addresses to be interviewed 24 times a year (and not 52), that is, the distance between two work packages is two weeks, except for the end of each quarter when it is three. This contributes further to the uneven distribution and leads to a situation in which relatively few respondents are being interviewed at the end of each quarter (for details, see Körner and Puch 2011). Nevertheless, no significant correlation is observed between the weekly sample size and the average number of hours actually worked observed for each week. Even in the unweighted data, the correlation coefficient is no larger than 0.013 , so that the effect of the numerical distribution of the sample over the weeks on working-time estimates is negligible (a rough estimation shows an effect of below 0.1 hours).

Still, the principle of the sliding reference week plays a more important role in another respect. It can be assumed that respondents are unlikely to make an appointment for a faceto-face interview in a week directly following an absence, for example, after one week of holiday. If the interview then "slides" to the next calendar week, the reference week will no longer be the one in which the respondent was absent. In other words, respondents who were on leave in the reference week would be systematically underrepresented in the sample. Based on the data available, it is unfortunately very difficult to analyse whether such effects might be empirically relevant. Some information can be gained from looking at the delay between the day the interviewers are provided with their work packages and the time the interviews are actually carried out. On average, $25.5 \%$ of the interviews take place in the first possible week after the distribution of a new work package. In weeks outside the usual holiday periods, this share amounts to nearly $30 \%$, while it is only $23 \%$ if the interview week falls inside usual school holidays and $22 \%$ in weeks directly following the usual school holidays. This could be interpreted as an indication that respondents are more difficult to reach directly following an absence and that the reference week then "slides" to a week in which they are no longer absent. Although the share of interviews within the first week of receiving a new work package is not a sufficient basis on which to quantify potential effects (as nothing is known regarding the actual absences of these respondents), it suggests that the effect on estimates of hours actually worked might be substantial. 


\subsection{Measurement Bias}

The most obvious source of error is measurement bias. Measurement bias includes a vast array of different error types, ranging from effects due to the data collection mode, effects due to proxy interviewing, effects due to the measurement instrument, and the interviewer. The conceptual backbone that helps respondents to understand the mechanisms leading to measurement bias is the cognitive process of answering survey questions. We will first present the data available on effects due to the data collection mode, proxy effects, and the structure and wording of the questionnaire, and then discuss these results in the context of the cognitive processes at play when formulating a survey response regarding the hours actually worked.

There are many reasons why the data collection mode may affect survey measurement. The type of social interaction and of communication, mode-specific questionnaire design options, as well as the use of computer assistance may contribute to differential measurement (for an overview, see Körner 2014). Studying mode effects requires a specific - ideally experimental - design, either with a split-sample, re-interview, or record-linkage design or at least with a reweighting of the data. None of these approaches was implemented for the present study. Despite this limitation, the comparison of LFS data can provide some insight as regards the hours actually worked, as data from an experimental study is able to corroborate the findings in the German case. In the case of France, CAPI is used in the first interview, while CATI is the predominant mode in follow-up interviews, so that the groups can be considered to be roughly structurally equivalent.

Both the German and the French data show a slight but significant difference between CAPI and CATI (see Table 9). The differences are larger for the self-administered paperand-pencil questionnaire that is used in Germany, but not in France. In the case of Germany, it could be argued that the telephone interviews, as well as the use of the selfadministered PAP questionnaire, concern rather specific groups. The results of an experimental study on mode effects largely confirm these results (Körner and Liersch 2014): while there were almost no differences between CATI and CAPI in this experiment, the average hours actually worked determined from the PAP (35.2 hours) was higher than in CAPI or CATI (34.3). However, these differences were still not significant, which might also be due to the limited sample size in this experiment.

Table 9. Hours actually worked per week by data collection mode, 2012 (full-time employees)

\begin{tabular}{llrlrr}
\hline & \multicolumn{2}{c}{ Germany } & & \multicolumn{2}{c}{ France } \\
\cline { 2 - 3 } & hours & & & hours & $\%$ \\
\hline Total & 35.8 & 100 & & 32.4 & 100 \\
CAPI & 35.5 & 66 & & 32.2 & 32 \\
CATI $^{(1)}$ & 36.0 & 9 & & 32.5 & 68 \\
Self-administered PAP & 36.7 & 25 & & N.A. \\
\hline
\end{tabular}

(1) Germany: Telephone interviews administered by field interviewers and "passive" telephone interviews administered by the state statistical office (both only partly computer assisted).

France: CAPI and CATI administered by Insee field interviewers. First and last contacts with interviewees have to be CAPI, and interviews in-between (hence Waves 2, 3, 4, and 5) are administered by telephone by the interviewer who has established the contact (unless the household insists on continuing face-to-face). 
Table 10 provides further insight into the different measurements underlying the different averages. While once again the distributions of data collected via CAPI and CATI are very close in both countries (no significant differences), PAP respondents are more likely to report a weekly working time of more than 40 hours. Correspondingly, the share of PAP respondents reporting 20 to 39 hours is significantly lower. Given that the share of PAP cases in the German LFS is $25 \%$, the effect on the overall average of the hours actually worked is smaller than 0.3 hours (under the unrealistic assumption that the entire difference is due to a measurement effect).

Effects due to proxy responding are another obvious effect in household surveys, that is, answers provided to questions that refer to another member of the household. It is often assumed that proxy answers are less accurate, mainly because the proxy respondents do not have the necessary information to answer survey questions properly at their disposal. Despite the popularity of using proxy effects to explain the issues experienced with measurements, very few experimental studies have been carried out in an LFS context, and those that do exist rarely focus on working time. One exception is the study by Ole Villund $(2009,5)$, who concluded in a record-linkage study regarding the contractual hours of work that "proxy interviews seem to cause more overestimation of contractual working hours, especially in jobs with varying contractual working hours and long hours." The data from the LFS only partly confirm this finding: As shown in Table 11, the average hours actually worked by full-time employees are higher in the case of proxy answers in France as in Germany. The difference is 1.4 hours in both countries. Again, these findings should be treated with caution as proxy interviews are not randomly allocated in groups in the LFSs, so some of the difference might be in differential working-time patterns of proxy respondents.

Table 12 clarifies that the differences in the average are due to a greater emphasis on the usual number of hours and not simply an overestimation of working hours in proxy interviews. The responses given by proxy respondents tend towards the modal value (40 hours in Germany and 35 hours in France) more frequently than in direct interviews. Similarly, proxy interviewees more rarely indicate that the reference person did not work at all in the reference week, a finding that again is consistent in both countries. Finally,

Table 10. Full-time employees by number of hours actually worked and data collection mode, 2012 (percentage of all full-time employees)

\begin{tabular}{|c|c|c|c|c|c|}
\hline & \multicolumn{3}{|c|}{ Germany } & \multicolumn{2}{|c|}{ France } \\
\hline & PAP $\%$ & CAPI $\%$ & $\mathrm{CATI}^{(1)} \%$ & CAPI $\%$ & CATI $\%$ \\
\hline Did not work in reference week & 11.4 & 11.5 & 11.5 & 14.9 & 14.5 \\
\hline $1-19$ hours & 1.3 & 1.6 & 1.2 & 2.4 & 2.0 \\
\hline 20-29 hours & 1.4 & 2.3 & 2.1 & 7.2 & 6.9 \\
\hline $30-34$ hours & 3.4 & 5.4 & 5.1 & 5.8 & 5.5 \\
\hline 35 hours & 3.8 & 4.5 & 4.9 & 22.2 & 23.9 \\
\hline $36-39$ hours & 14.2 & 17.0 & 16.9 & 18.9 & 19.1 \\
\hline 40 hours & 34.3 & 34.7 & 33.7 & 9.1 & 9.4 \\
\hline $41-49$ hours & 18.6 & 13.7 & 14.2 & 11.0 & 10.3 \\
\hline 50 hours or more & 11.6 & 9.3 & 10.6 & 8.5 & 8.5 \\
\hline
\end{tabular}


Table 11. Hours actually worked per week by proxy interview, 2012 (full-time employees)

\begin{tabular}{lcrllr}
\hline & \multicolumn{2}{c}{ Germany } & & \multicolumn{2}{c}{ France } \\
\cline { 2 - 3 } \cline { 5 - 6 } & hours & $\%$ & & hours & $\%$ \\
\hline Total & 35.8 & 100 & & 32.4 & 100 \\
Proxy & 36.8 & 25 & & 33.4 & 29 \\
Non proxy & 35.4 & 75 & & 32.0 & 71 \\
\hline
\end{tabular}

particularly long working hours are indicated more rarely in proxy interviews, at least in the case of Germany. These results suggest that the question on hours actually worked is sensitive to proxy effects and can have a substantial impact on the implausible results presented in Section 3. However, it can explain only part of the differences between France and Germany, as the proxy rate in both countries is similar (see Chapter 2).

Mode effects and proxy effects, as well as other types of measurement bias, can originate from any of the cognitive steps in the survey response. The standard cognitive steps of survey response are considered to be: comprehension, retrieval, judgement, and reporting (Tourangeau et al. 2000; for an overview, see Biemer and Lyberg 2003, 123-148). Applied to questions on working time, these steps can be presented as follows: the respondent needs to understand the question, in particular the underlying concepts, that is, the items to be included and excluded as well as the reference concepts (reference week, focus on the main job). Having understood which information he or she is expected to provide, the respondent needs to retrieve the necessary information, that is, remember the reference week in question, the working hours undertaken, including any absences from work or overtime. In a household survey, respondents will usually have to rely on their memory to perform this task, although it would probably be useful if they checked with their calendar. In the judgement step, the respondent needs to assess the information retrieved regarding its completeness and relevance to the question, taking into account the required response format. In the case of working-time questions, this includes some kind

Table 12. Full-time employees by number of hours actually worked and proxy/direct interview, 2012 (percentage of all full-time employees)

\begin{tabular}{|c|c|c|c|c|}
\hline & \multicolumn{2}{|c|}{ Germany } & \multicolumn{2}{|c|}{ France } \\
\hline & $\begin{array}{c}\text { Proxy } \\
\text { interview \% }\end{array}$ & $\begin{array}{c}\text { Direct } \\
\text { interview } \%\end{array}$ & $\begin{array}{c}\text { Proxy } \\
\text { interview \% }\end{array}$ & $\begin{array}{c}\text { Direct } \\
\text { interview \% }\end{array}$ \\
\hline $\begin{array}{l}\text { Did not work in } \\
\text { reference week }\end{array}$ & 8.8 & 12.5 & 13.0 & 15.3 \\
\hline $1-19$ hours & 1.1 & 1.7 & 1.5 & 2.4 \\
\hline 20-29 hours & 1.8 & 2.2 & 6.3 & 7.3 \\
\hline $30-34$ hours & 5.1 & 5.0 & 4.4 & 6.1 \\
\hline 35 hours & 4.0 & 4.6 & 28.0 & 21.3 \\
\hline $36-39$ hours & 16.1 & 16.5 & 17.8 & 19.5 \\
\hline 40 hours & 42.7 & 31.5 & 9.4 & 9.2 \\
\hline 41-49 hours & 10.9 & 16.1 & 9.8 & 10.8 \\
\hline 50 hours or more & 9.5 & 9.9 & 9.8 & 8.0 \\
\hline
\end{tabular}


of calculation, either by adding up the daily working time or, more frequently, by deducting absences from a usual week and adding on any overtime. Finally, the respondent needs to provide the response, which may deviate from the result obtained in the judgement phase. In working-time questions respondents commonly round off, but the respondent may also over- or understate his or her working time with regard to social norms. It should be noted that the cognitive steps are distinguished analytically but often take place simultaneously.

The French and the German questionnaires have found different solutions to help the respondent provide the correct response. Starting with the comprehension stage, the German questionnaire, following the question ("How many hours did you actually work in the last week?"), restricts the explanation of the concepts to a short instruction saying "The number of hours actually worked may differ from the hours usually worked because of overtime, holidays, extra shifts, public holidays, illness and the like. The number of hours actually worked includes continuing and advanced training, stand-by duty, work done at home provided that it is a normal part of your job, such as for teachers." Note that, despite its length, this instruction already omits some of the elements outlined in Section 2, tacitly assuming that they correspond to a common perception (such as the distinction between coffee breaks and lunch breaks). In the context of an interviewer-administered survey, it is probably doubtful that this instruction would be read out to the respondent in any case. According to the concept of sliding reference weeks, the question refers to the reference week as "last week", which omits the specific date. The question does not contain a specific cue to remind the respondent that the response should refer only to their main job (provided once at the beginning of the module on the characteristics of the main job). This is an important element, as recent cognitive tests have shown that multiple job-holders have a tendency to sum up the working hours in all of their jobs (Vallé et al. 2014).

The French questionnaire has similar instructions, but introduces the main components of the working-time concepts in a series of dedicated questions asking specifically about absences due to paid leave, compensated leave, or sick leave, slack periods of work, training, labour disputes and extra time worked due to overtime hours. The duration of each type of absence and overtime is measured with dedicated questions. It is only after a series of about 20 questions has been answered that the question on hours actually worked appears ("(In total) In the week from Monday [. . .] to Sunday [. . .], how many hours did you actually work in your main job?”). The instruction below the question on hours actually worked therefore serves simply as a reminder: "Do not count hours or days of ordinary holiday, special leave, public holidays, compensated leave, unpaid leave, partial unemployment, education and training, strike, labour dispute". It is easy to imagine that the respondent will be more familiar with the deductions and additions needed to come up with a correct reply regarding the hours actually worked. In contrast to the instruction in the German questionnaire, the French one mentions only deductions, and not any overtime that would have to be included in the answer. Further differences are that the precise dates of the reference week are mentioned in the French questionnaire ("from Monday, . . . , to Sunday, ...") and that the French question explicitly specifies the reference to the main job. Table 13 provides the original question wording as well as an English translation.

It seems obvious that the questions regarding absences and overtime applied in the French questionnaire not only help to ensure that the complex concept is understood, but 
Table 13. Questions on hours actually worked in the LFS questionnaires in France and Germany (2012) ${ }^{(1)}$

Germany France

\section{Original version}

Wie viele Stunden haben Sie in der letzten Woche tatsächlich gearbeitet?

Die tatsächliche Arbeitszeit kann von der normalerweise geleisteten Arbeitszeit abweichen, zum Beispiel wegen Überstunden, Urlaubstagen, Sonderschichten, Feiertagen, Krankheit o. Ä.

Zur tatsächlichen Arbeitszeit gehören auch Weiter- und Fortbildungen, Bereitschaftszeiten, Arbeiten von zu Hause, sofern sie Bestandteil Ihrer Erwerbstätigkeit sind, z. B. bei Lehrkräften.
(Au total) La semaine du lundi ... au dimanche . . ., combien d'heures avez-vous effectuées dans votre emploi principal?

(Ne pas compter les heures ou jours de congés ordinaires, exceptionnels, fériés, ponts, RTT, récupération, congé personnel non rémunéré, chômage partiel, activité de formation, grève, conflit du travail)

\section{English translation}

How many hours did you actually work in the last week?

The number of hours actually worked may differ from the hours usually worked because of overtime, holidays, extra shifts, public holidays, illness and the like. The number of hours actually worked includes continuing and advanced training, stand-by duty, work done at home provided that it is a normal part of your job, such as for teachers.
"(In total) In the week from Monday [. . . ] to Sunday [. . .], how many hours did you actually work in your main job?"

Do not count hours or days of ordinary holiday, special leave, public holidays, compensated leave, unpaid leave, partial unemployment, education and training, strike, labour dispute

(1) The full LFS questionnaires are available at http://ec.europa.eu/eurostat/statistics-explained/index.php/ EU_labour_force_survey_-_methodology\#Core_questionnaires

also facilitate the retrieval of the necessary information. It is however difficult to obtain direct empirical evidence on the cognitive process from quantitative data. Nevertheless, a qualitative pretest of a working-time questionnaire module inspired by the French approach carried out at the Federal Statistical Office Germany indicates that a vast majority of respondents found it helpful for the question on hours actually worked to be introduced after a sequence of questions of absences and extra time. However, only few respondents in this test were actually absent in the reference week (Vallé et al. 2014).

Another important potential source of error at the retrieval stage is memory effect: the longer the time span between the reference week and the interview, the more difficulty respondents will have in comprehensively retrieving the necessary information. For this reason, the legal act mandating the LFSs (Council Regulation No. 577/1998) stipulates that "the interview normally takes place during the week immediately following the reference week". As in the German design the reference week is by definition the week before the interview, memory effects can only be analysed for the French LFS. After the cognitive step 
of information retrieval, the steps of judgement and reporting follow, and in both cognitive processes the phenomenon of rounding is observed. As shown in Figure 2, there is clear empirical evidence that respondents make use of rounding when preparing and reporting their responses. Rounding is obviously not restricted to the next whole number, but extends to numbers divisible by 5: Conspicuous peaks can be seen for all numbers ending in a " 5 " or a " 0 ", in both Germany and France. While one might argue that the modal values (35 in France and 40 in Germany) could actually represent the most frequent weekly working time, the peaks for the rest of the distribution clearly indicate the effect of rounding. Even the high percentage of respondents indicating 40 hours in Germany does not seem entirely plausible: the average contractual hours of work laid down in collective agreements in 2012 were 38.3 hours, and almost all economic activity groups had working hours fixed by collective agreements of less than 40 hours (except for the NACE rev. 2 divisions "construction of buildings" and "civil engineering", in which working hours equalled 40 hours; see Statistisches Bundesamt 2014). In Germany, one would expect higher percentages for 38 and 39 hours and a lower percentage for 40 hours. For France, 35 hours is a national legal threshold beyond which the employer has to pay overtime. Since 2008 however, branches and firms have the possibility of renegotiating this threshold at their convenience. Many branches have done so, so it is now hard to give an average duration. According to an estimation by the Direction de l'animation de la recherche, des études et des statistiques (DARES), the average collective agreed working hours in France amount to 35.6 hours (Eurofound 2013). Beyond that, the "35-hour" theme has become a political slogan and is omnipresent in public debate. This is why it is no surprise that there is a peak in the responses at 35 hours (Figure 2). It is still difficult to distinguish between the actual hours and the rounding effects.

Although the rounding effect is clear both for France and for Germany, it seems to be slightly more frequent in Germany: $54.2 \%$ of the responses given to the question on hours actually worked end in a " 5 " or a " 0 ", while this is the case for only $47.9 \%$ of the responses

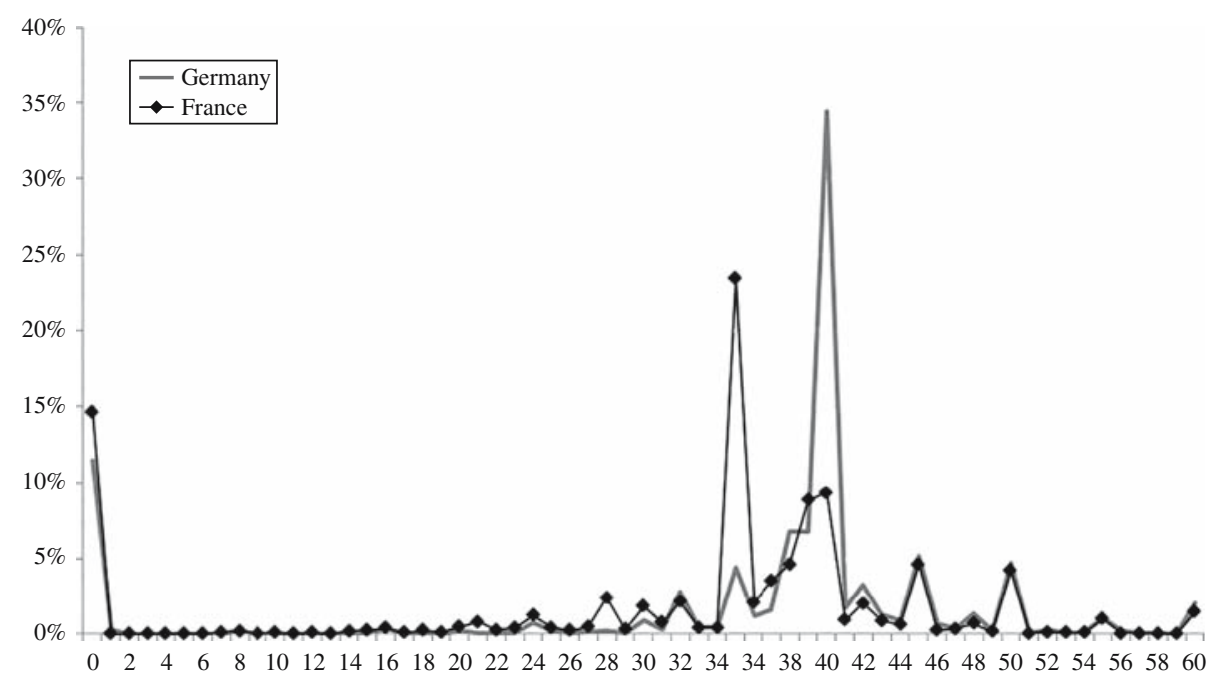

Fig. 2. Distribution of hours actually worked (full-time employees, 2012) 
in France. Greater use of rounding in Germany can also be assumed when comparing the questionnaires: While respondents in Germany are required to answer in whole numbers and are explicitly invited to round ("Round up or down to the nearest full hour"), respondents in the French LFS are asked to give their answer to one decimal place.

Rounding off may explain most of the difference between the French and German results. Given the working-time provisions in the law as well as in collective agreements, it seems likely that the peaks for 35 hours in France and 40 hours in Germany suggest that rounding in France usually means rounding down, while in Germany it is more likely to mean rounding up.

\subsection{Editing Effects}

The data provided by the respondents might also be influenced by edit checks applied during data collection. Both Germany and France apply edit checks during the interview itself, using both soft checks (asking to verify the response given) and hard checks (requiring a change in the response given in order to be able to proceed with the interview). In the context of measuring hours actually worked in Germany, two plausibility checks are particularly relevant. Both refer to the measurement of the employment status in the reference week (EU-LFS variable WSTATOR), for which respondents have to indicate whether they worked for at least one hour in the reference week (WSTATOR $=1$ ) or whether they had a job from which they were absent in the reference week $($ WSTATOR $=2$ ). For respondents coded WSTATOR $=2$, in Germany there was a hard check applied to the question on the number of hours actually worked: persons who answered that they worked for at least one hour in the reference week were not allowed to answer " 0 " to the question on hours actually worked, while those who reported having not been at work in the reference week were requested to report zero hours. Both checks were implemented as hard checks, that is, the respondent could only continue the interview after having corrected his or her response. For instance, the first plausibility check might be problematic: the absence from the job is not the main purpose of the variable WSTATOR, but was initially included to make sure that all employed persons were captured, even if temporarily not at work. Furthermore, in the German translation of "having worked last week", it is not entirely clear whether this includes absences, for example, due to paid leave (Nebel et al. 2013). Therefore it seems likely that the questions on the employment status do not entirely cover the absence of employed persons in the reference week. As a result, respondents might be pushed to omit information on absences in the reference week when asked for the hours actually worked, much later in the questionnaire. It is difficult to find empirical data to substantiate this speculation. Some, albeit limited, insight can be gained from an experimental study on measurement effects due to the data collection mode, carried out by the Federal Statistical Office together with eight State Statistical Offices in 2009 and 2010 (see Körner and Liersch 2014; Statistisches Bundesamt 2010). In this split-sample experiment, the edit checks were applied to the interviewer-administered data collection modes (CAPI and CATI), but not to the self-administered modes. In a tabulation of the experimental data set produced for this article, it was shown that the answers provided to both questions were inconsistent in 5\% to $16 \%$ of the responses when no edit checks were performed. While the PAP self-administered questionnaires show no 
clear pattern, the online questionnaire tested among the implausible answers contains almost only cases that stated they did work in the reference week, but reported zero hours when asked for the hours actually worked. The difference in the percentage of full-time employees having worked zero hours in the reference weeks in the online mode was $11 \%$ without edit checks compared to $7 \%$ with edit checks, and $12 \%$ and $9 \%$ respectively in the self-administered PAP mode (note that the reference period did not cover the entire year, so a comparison with regular LFS data is not possible). Despite the small sample size and the corresponding low statistical power, this result suggests that effects of this type could have a substantial impact. In France, no hard checks have been implemented for these questions: it is possible for a respondent to simultaneously declare having worked and declare a duration of zero hours. Regarding this specific issue, the French questionnaire is more flexible than the German one. The opposite, however, is not possible in France: a respondent declaring not having worked during the reference week cannot later in the questionnaire give a number of hours worked. To the best of our knowledge, the impact of this filter has not been tested: respondents may give inconsistent answers and give a positive number of hours worked, despite their answer to WSTATOR (for part-time and casual work, for instance).

\section{Conclusions}

The various issues raised in this contribution show that any comparison of hours actually worked in Germany and France is a complicated affair, since the conditions for ensuring the robust comparability of data are not met.

The main issue is with the measurement of hours not worked during the reference week: given the structures of questionnaires, the effects of rounding off, the sampling design, and the use of data editing, the way this information is collected is heterogeneous and leads to divergent estimates. The study of French and German cases clearly highlights this limitation. The differences in Germany and France regarding the measurement of working time and absences are a concern not only in these two countries, but should be raised for all EU member states. The differences shown here between Germany and France are in fact rather slight when compared with the results for countries like Romania (with only $1.9 \%$ of full-time employees totally absent from work in the reference week), Bulgaria (2.9\%), Greece $(3.5 \%)$ or Hungary $(4.0 \%)$. If taken seriously, these statistics demonstrate that employees in these countries very rarely take holidays or days off from work at all. Conversely, countries like Sweden (15.6\%), Finland (15.0\%) and France (14.6\%) show the highest rates of full-time employees absent during the reference week. In this regard, Germany appears to be amongst the countries where the underreporting of absences is the lowest (see Table 14 in the Appendix).

Overall, as French full-time employees seem to work 3.4 hours less than Germans (respectively 35.8 hours and 32.4 hours actually worked in the reference week in Germany and France), the difference is reduced to 2.0 hours when only considering respondents who worked not less than usual in the reference week (41.9 hours in Germany and 39.9 hours in France). In the same way, the difference regarding the average hours usually worked is much smaller: regarding this concept, which focuses on a typical week (thus largely disregarding any periods of absence), the average working time in Germany (40.7 hours) is 
only 1.3 hours more than in France (39.4). These uncertainties demonstrate that the international comparability of hours actually worked is limited in the LFS data and that the results require very careful interpretation. However, when making comparisons of the results for the hours usually worked it needs to be borne in mind that the measurement of this variable might be subject to specific measurement effects as well, which cannot be dealt with in the context of this contribution.

This methodological issue can have an impact on the public debate. Unless sufficient care is taken, comparisons based on these data can lead to false conclusions regarding "insufficient" or "excessive" working time either in France or Germany. Given the importance of these issues, we would like to emphasise the need to make the data collected throughout Europe more comparable, notably concerning the measurement of the hours actually worked. We hope that this contribution will help to push this issue further up the European agenda and help countries to find a convergent position.

Within the European Statistical System, the first conclusions have already been drawn: in April 2013, a Task Force on the Measurement of Absences and Working Time was created by Eurostat and the EU member states. The Task Force's main objective is to develop a model questionnaire to help improve and harmonise the measurement of the different working-time concepts in the EU-LFS. The draft model questionnaire addresses many of the issues raised in this contribution: it is based on a similar approach to that used in France, but is considerably simplified in order to ensure its implementation is feasible in all member states. The question on the number of hours actually worked in the reference week is preceded by a series of questions regarding absences from work due to public holidays, holidays and time off in lieu, as well as sick leave and other reasons. Two further questions focus on overtime in the reference week, which also needs to be considered when asking for the number of hours actually worked. A first round of empirical tests showed promising results but revealed a number of different problems, for instance in the case of irregular working hours, shift work, and part-time work. A revised version of the model questionnaire is currently being tested in other member states (Eurostat 2014a). Although this work is considered extremely important to improve cross-national harmonisation, it should be noted that a model questionnaire alone cannot guarantee comparability of the results. As we have shown, differences in the data collection modes, the share of proxy interviews, as well as the allocation of the reference weeks can have substantial impact on the measurement of the hours actually worked as well. It should be investigated further whether further harmonisation is possible regarding these critical elements, or at least whether experimental studies could be established to quantify the magnitude of the effects. With regard to the measurement of working time, it would in particular be desirable to reduce the rate of proxy interviews. Regarding mode effects, the introduction of web interviewing in LFSs (currently fostered by many national statistical institutes) may be a particular challenge. Further experimental research is needed to learn more about the potential impact of web interviewing on working-time estimates.

In the meantime, we would encourage users to make cautious use of the variables related to working time in the LFS, in particular the hours actually worked. Until further methodological improvements have been made, it is difficult to draw robust conclusions from these data, for instance regarding international comparisons. For international comparisons, users should use information regarding the hours usually worked or refer to 
the hours actually worked for respondents who worked at least one hour in the reference week (current publication at the Eurostat online database).

However, this contribution does demonstrate that analyses of LFS data are possible and can be highly profitable. The results shown here would benefit from being replicated in all member states. The issues might differ from a country to another, as the questionnaires and sample designs for the LFSs are only partially comparable throughout Europe.

Cognitive tests and qualitative approaches to investigate respondents' behaviour, in a comparative framework, together with quantitative experimental studies, would also improve our understanding of these surveys and their divergences.

\section{Appendix}

Table 14. Percentage of employed persons having worked less than usual in the reference week, full-time employees (LFS, 2012)

\begin{tabular}{|c|c|c|c|}
\hline & \multicolumn{2}{|c|}{ Hours actually worked } & \multirow[b]{2}{*}{ Average hours actually worked } \\
\hline & 0 hours $\%$ & more than 0 hours $\%$ & \\
\hline Austria & 12.2 & 20.4 & 35.3 \\
\hline Belgium & 10.5 & 10.7 & 34.2 \\
\hline Bulgaria & 2.9 & 5.3 & 39.1 \\
\hline Croatia & 5.9 & 7.5 & 37.9 \\
\hline Cyprus & 6.4 & 11.4 & 37.7 \\
\hline Czech Republic & 7.6 & 12.7 & 37.2 \\
\hline Denmark & 13.2 & 12.1 & 33.5 \\
\hline Estonia & 6.3 & 14.0 & 37.5 \\
\hline EU-28 & 9.8 & 12.5 & 35.8 \\
\hline Finland & 15.0 & 21.9 & 31.9 \\
\hline France & 14.6 & 18.9 & 32.2 \\
\hline Germany & 11.5 & 10.7 & 35.8 \\
\hline Greece & 3.5 & 5.9 & 38.6 \\
\hline Hungary & 4.0 & 10.8 & 37.9 \\
\hline Ireland & 8.9 & 10.0 & 34.9 \\
\hline Italy & 9.4 & 7.6 & 34.5 \\
\hline Latvia & 6.0 & 3.8 & 37.5 \\
\hline Lithuania & 7.3 & 2.5 & 36.7 \\
\hline Luxembourg & 12.0 & 7.1 & 36.2 \\
\hline Malta & 5.4 & 17.6 & 37.5 \\
\hline Netherlands & 11.6 & 13.9 & 35.1 \\
\hline Poland & 6.2 & 9.8 & 37.6 \\
\hline Portugal & 9.4 & 13.1 & 36.4 \\
\hline Romania & 1.9 & 0.8 & 40.4 \\
\hline Slovakia & 6.4 & 13.3 & 37.1 \\
\hline Slovenia & 12.3 & 13.1 & 34.7 \\
\hline Spain & 9.5 & 10.8 & 35.7 \\
\hline Sweden & 15.6 & 21.7 & 32.6 \\
\hline United Kingdom & 9.0 & 18.5 & 37.4 \\
\hline
\end{tabular}

Source: Eurostat, own calculations. 


\section{References}

Biemer, P. and L. Lyberg. 2003. Introduction to Survey Quality. Hoboken, NJ: Wiley. Blanke, K. and A. Luiten. 2014. Query on Data Collection for Social Surveys. ESSnet Project "Data Collection for Social Surveys using Multiple Modes". Available at: http://www.cros-portal.eu/content/data-collection (accessed 18 December 2014).

Coe-Rexecode. 2012. La durée effective du travail en France et en Europe. Document de Travail no. 29. Paris: Coe-Rexecode. Available at: http://www.coe-rexecode.fr/public/ content/download/32364/323546/version/2/file/Document-de-travail-Coe-RexecodeDuree-effective-du-travail-Fance-Europe-2012-29.pdf (accessed 8 April 2016).

Coe-Rexecode. 2014. La durée effective du travail en France et en Europe. Résultats de 2013 et mise à jour de l'étude de 2012. Document de Travail no. 49. Paris: CoeRexecode. Available at: http://www.coe-rexecode.fr/public/content/download/34852/ 351622/version/3/file/Doc-trav-49-Duree-du-travail-France-et-Europe-2013-Juin2014.pdf (accessed 8 April 2016).

Eurofound. 2013. Developments in Collectively Agreed Working Time 2012. Dublin: European Foundation for the Improvement of Living and Working Conditions. Available at: http://www.eurofound.europa.eu/docs/eiro/tn1305017s/tn1305017s.pdf (accessed 8 April 2016).

Eurostat. 2009. ESS Handbook for Quality Reports. Luxembourg: Office for Official Publications of the European Communities. Available at: http://unstats.un.org/unsd/ EconStatKB/Attachment286.aspx?AttachmentType=1 (accessed 8 April 2016).

Eurostat. 2013. Labour Force Survey in the EU, Candidate and EFTA countries. Main Characteristics of National Surveys, 2012. Luxembourg: Eurostat. Available at: http:// epp.eurostat.ec.europa.eu/portal/page/portal/product_details/publication?p_product _code=KS-TC-13-003 (accessed 13 August 2014).

Eurostat. 2014a. Interim Report of the Task Force on Measurement of Absences and Working Time. Working Group on Labour Market Statistics (LAMAS), June 2014. Document Eurostat/F3/LAMAS/07/14. Luxembourg: Eurostat.

Eurostat. 2014b. Quality Report of the European Union Labour Force Survey 2013. Luxembourg: Eurostat. Available at: http://ec.europa.eu/eurostat/documents/3888 793/6194252/KS-TC-14-010-EN-N.pdf/39a79a33-4442-49b6-b83f-f0a5e81b02ef (accessed 29 June 2015).

Fleck, S. 2009. "International Comparisons of Hours Worked: an Assessment of the Statistics." Monthly Labor Review 5: 3-31.

Frazis, H. and J. Stewart. 2004. "What Can Time-Use Data Tell Us About Hours of Work?" Monthly Labor Review 127: 3-9.

Groll, T. 2014. “Arbeitszeit: Deutsche arbeiten vergleichsweise wenig.” Zeit Online Beruf 13 May 2014. Available at: http://www.zeit.de/karriere/2014-05/arbeitszeit-oecd-infografik (24 October 2014).

Groves, R. 1989. Survey Errors and Survey Costs. Hoboken, NJ: Wiley.

Groves, R. et al. 2009. Survey Methodology, 2nd ed. Hoboken, NJ: Wiley.

IAB. 2014. Durchschnittliche Arbeitszeit und Ihre Komponenten in Deutschland. Nuremberg: Institut für Arbeitsmarkt- und Berufsforschung (IAB). Available at: http:// doku.iab.de/arbeitsmarktdaten/AZ_Komponenten.xlsx (accessed 21 October 2014). 
International Labour Organization (ILO). 2008. Resolution Concerning the Measurement of Working Time. Adopted by the Eighteenth International Conference of Labour Statisticians, November-December 2008. Geneva: International Labour Organization. Available at: http://www.ilo.org/global/statistics-and-databases/standards-and-guide lines/resolutions-adopted-by-international-conferences-of-labour-statisticians/WCMS_112455/lang-en/index.htm (accessed 11 August 2014).

Körner, T. 2012. "Measuring the Labour Status in Official Statistics: The Labour Force Concept of the International Labour Organisation and its Implementation in the Labour Force Survey." In Demographic Standards for Surveys and Polls: National and European Dimensions, edited by J. Hoffmeyer-Zlotnik and U. Warner, 123-138. Cologne: GESIS 2012.

Körner, T. 2014. "Report on the Definition, Identification and Analysis of Mode Effects." Deliverable for Work Package III of the ESSnet on Data Collection for Social Surveys Using Multiple Modes, Wiesbaden: Federal Statistical Office Germany. Available at: http://www.cros-portal.eu/content/data-collection (accessed 18 December 2014).

Körner, T. and A. Liersch. 2014. "Case Study on Mode Effects in the Germany Labour Force Survey." Deliverable for Work Package III of the ESSnet on Data Collection for Social Surveys Using Multiple Modes. Wiesbaden: Statistisches Bundesamt. Available at: http://www.cros-portal.eu/content/data-collection (accessed 18 December 2014).

Körner, T. and K. Puch. 2011. Coherence of German Labour Market Statistics. Vol. 19 of Statistics and Science. Wiesbaden: Statistisches Bundesamt.

Lefèvre, L. J. Rakotomalala, and F. Toutlemonde. 2012. "Méthodologie des comptes annuels de l'emploi, des heures travaillées et de la durée du travail dans la base 2005 de la comptabilité nationale." Note méthodologique des comptes nationaux, Insee.

Loriga, S. and A. Spizzichino. 2013. "Working hours: Analysis of Italian LFS Results versus Administrative Data and Business Survey." Paper presented at the 8th Workshop on Labour Force Survey Methodology, Gdansk, Poland, 23-24 May 2013. Available at: http://old.stat.gov.pl/lfs2013/papers/F3_Silvia_Loriga,Andrea_Spizzichino_IT.pdf (accessed 24 October 2014).

Massarelli, N. 2011. "Harmonisation Issues for the Measurement of Employment and Unemployment." Paper presented at the 6th Workshop on LFS Methodology, Wiesbaden, Germany, 12-13 May 2011. Available at https://www.destatis. de/EN/AboutUs/Events/LFS/PapersP/G1_HarmonisationIssues_Massarelli.pdf?_blo$\mathrm{b}=$ publicationFile (accessed 24 October 2014).

Mata Greenwood, A. 2001. "The Hours that We Work: The Data We Need, the Data We Get." ILO Bulletin of Labour Statistics 2001-1

Nebel, S. et al. 2013. Implementation Study of the Model Questionnaire for the Measurement of Employment and Unemployment and the Variables of the ad hoc Module 2015 on Work Organisation and Working Time Arrangements. Final report, European Commission Grant Agreement No. 10201.2012.001-2012.961, Wiesbaden: Statistisches Bundesamt.

Niemi, I. 1993. "Systematic Error in Behavioural Measurement." Social Indicators Research 30: 229-244. 
OECD. 2004. OECD Measures of Total Hours Worked. The OECD Production Database, March 2004. Available at www.oecd.org/std/productivity-stats/29867131.pdf (accessed 10 August 2014).

Robinson, J. et al. 2011. "The Overestimated Workweek Revisited." Monthly Labor Review 134: 43-53.

Robinson, J. and A. Bostrom. 1994. "The Overestimated Workweek? What Time Diary Measures Suggest." Monthly Labor Review August 1994: 11-23.

Spitznagel, E. 2003. "Hours and Volume of Work in Germany The IAB Concept of Measurement." Paper presented at the Paris Group Meeting, 4-5 September 2003, London. Available at: http://www.insee.fr/en/insee-statistique-publique/colloques/ citygroup/pdf/Germany-Session2.pdf (accessed August 2014).

Statistisches Bundesamt. 2010. Ergebnisse des Projektes Q-MED/LFS. Quantifizierung von Methodeneffekten unterschiedlicher Erhebungsinstrumente auf die Datenqualität im Labour Force Survey. Ein Gemeinschaftsprojekt der Statistischen Ämter des Bundes und der Länder zur Qualitätssicherung im Mikrozensus/Labour Force Survey. Wiesbaden: Statistisches Bundesamt.

Statistisches Bundesamt. 2014. Verdienste und Arbeitskosten. Index der Tarifverdienste und Arbeitszeiten 2. Vierteljahr 2014. Fachserie 16 Reihe 4.3, Wiesbaden: Statistisches Bundesamt. Available at: https://www.destatis.de/DE/Publikationen/Thematisch/VerdiensteArbeitskosten/Tarifverdienste/Tarifverdienst2160430143224.pdf?__blob= publicationFile (accessed September 2014).

Tourangeau, R., L. Rips, and K. Rasinski. 2000. The Psychology of Survey Response. Cambridge: Cambridge University Press.

Vallé, J. et al. 2014. Implementation Study of the Model Questionnaire for the Measurement of Absences and Working Time and the ad hoc Module 2016 on Young People on the Labour Market. Final report, European Commission Grant Agreement no. 07131.2013.001-2013.372, Wiesbaden: Statistisches Bundesamt.

Villund, O. 2009. Measuring Working Hours in the Norwegian Labour Force Survey: A Pilot Study of Data Quality Using Administrative Registers. Report 2009/3, Oslo-Kongsvinger: Statistisk sentralbyrå.

Wanger, S. 2013. "Arbeitszeit und Arbeitsvolumen in Deutschland - Methodische Grundlagen und Ergebnisse der Arbeitszeitrechnung." Wirtschafts- und Sozialstatistisches Archiv 7: 31-69.

Williams, R. 2002. "Hours Worked: A Comparison of Estimates from the Labour Force and New Earnings Survey." Labour Market Trends 110: 429-441.

Williams, R. 2004. "Investigating hours worked measurements." Labour Market Trends 112: $71-80$.

\section{Legal Texts}

Commission Regulation (EC) no 377/2008 of 25 April 2008 Implementing Council Regulation (EC) no 577/98 on the Organisation of a labour Force Sample Survey in the Community As Regards the Codification to Be Used for Data Transmission from 2009 Onwards, the Use of a sub-sample for the Collection of Data on Structural Variables and 
the Definition of the Reference Quarters. Official Journal of the European Union, 26 April 2008, L 114/57.

Council Regulation (EC) no 577/98 of 9 March 1998 on the Organisation of a labour Force Sample Survey in the Community. Official Journal of the European Union, 14 March 1998, L 77/3.

Received December 2014

Revised July 2015

Accepted September 2015 